\title{
ESTUDO E REQUALIFICAÇÃO DO ALVORADA CLUBE EM CRICIÚMA (SC), UMA PRÁTICA COLABORATIVA ENTRE UNIVERSIDADE E COMUNIDADE
}

\author{
Dyene Mafioletti ${ }^{1}$ \\ Jorge Luiz Vieira ${ }^{2}$ \\ Geferson Rafael da Rosa ${ }^{3}$ \\ Júlia Valim Bauer ${ }^{4}$ \\ Franciny Cechinel de Souza ${ }^{5}$
}

\begin{abstract}
Resumo: Este artigo apresenta de forma conceitual e prática a experiência acadêmica no estudo de caso e no processo de requalificação do Clube Alvorada em Criciúma, SC. O projeto atua por meio de uma prática colaborativa entre o Escritório Modelo Interdisciplinar - EMI da Universidade do Extremo Sul Catarinense - UNESC, a Associação de Professores e Funcionários da UNESC - APROFUCRI e a comunidade dos bairros Pinheirinho e Milanese, em Criciúma/SC. O EMI se desenvolve na perspectiva da interdisciplinaridade e das relações interinstitucionais, proporcionando aos alunos a incorporação dos conhecimentos teóricos e práticos, por meio da participação ativa nos projetos com orientação docente. Essa prática, além de possibilitar trocas de saberes entre a universidade e a comunidade, oferece aos discentes oportunidades de testarem habilidades e competências adquiridas, pela participação na solução de problemas reais inerentes ao seu campo de atuação. Sob esta perspectiva é que se desenvolve o projeto de requalificação do Alvorada Clube, que se localiza entre os bairros Pinheirinho e Milanese, atendendo cerca de 7.621 habitantes em suas imediações. O clube sediou os mais importantes eventos da comunidade local. O edifício, além do seu valor histórico, expressa uma linguagem tardia do modernismo, constituindo-se em importante acervo local a ser preservado e que atualmente encontra-se em mau estado de conservação. Desta forma, o Escritório Modelo teve como objetivo realizar o levantamento patrimonial do edifício a fim de produzir um estudo preliminar para a recuperação de suas instalações por meio da interação universidadesociedade.
\end{abstract}

Palavras chave: Extensão Universitária. Requalificação. Troca de Saberes.

Abstract: This article presents in a conceptual and practical way the academic experience in the case study and in the requalification process of Clube Alvorada in Criciúma, SC. The project works through a collaborative practice between the Interdisciplinary Model Office - EMI of the Universidade do Extremo Sul Catarinense - UNESC, the Teachers and Employees Association of UNESC and the community of the neighborhoods Pinheirinho and Milanese, in Criciúma / SC. The EMI develops from the perspective of interdisciplinarity and interinstitutional

\footnotetext{
${ }^{1}$ Bolsista no Escritório Modelo Interdisciplinar da Universidade do Extremo Sul Catarinense - UNESC.

${ }^{2}$ Professor e Coordenador do Escritório Modelo Interdisciplinar da Universidade do Extremo Sul Catarinense UNESC.

${ }^{3}$ Bolsista no Escritório Modelo Interdisciplinar da Universidade do Extremo Sul Catarinense - UNESC.

${ }^{4}$ Bolsista no Escritório Modelo Interdisciplinar da Universidade do Extremo Sul Catarinense - UNESC.

${ }^{5}$ Bolsista no Escritório Modelo Interdisciplinar da Universidade do Extremo Sul Catarinense - UNESC.
} 
relations, providing students with the incorporation of theoretical and practical knowledge through active participation in projects with a teaching orientation. This practice, in addition to enabling knowledge exchanges between the university and the community, offers students opportunities to test acquired skills and competences by participating in the solution of real problems inherent to their field of activity. From this perspective, the Alvorada Clube requalification project is being developed, located between the Pinheirinho and Milanese districts, serving around 7.621 inhabitants in its immediate vicinity. The club hosted the most important events of the local community. The building, in addition to its historical value, expresses a late language of modernism, constituting an important local heritage to be preserved and which is currently in poor condition. In this way, the Model Office aims to carry out the heritage survey of the building in order to produce a preliminary study for the recovery of its facilities through university-society interaction.

Keywords: University Extension. Requalification. Collaborative Practice. Exchange of Knowledge.

\section{INTRODUÇÃO}

A partir da reabertura política na década de 90 e do retorno das atividades nos Centros Acadêmicos e na Federação Nacional dos Estudantes de Arquitetura e Urbanismo - FeNEA, foram retomadas as discussões baseadas nas atividades práticas dos acadêmicos durante sua formação. No seguimento das discussões, na busca de imersão na comunidade, na liberdade da idealização, surge o Escritório Modelo de Arquitetura e Urbanismo - EMAU, um projeto de Extensão Universitária dentro da FeNEA. O EMAU caracteriza-se por ser uma entidade estudantil que realiza extensão universitária, parte indissociável da pesquisa e do ensino de graduação, buscando não somente o complemento da educação universitária, mas também o compromisso com a realidade social brasileira.

No ano de 2009, surge o embrião do Escritório Modelo Interdisciplinar da UNACETEMI, inicialmente por meio de um projeto de extensão que envolveu os cursos de Arquitetura e Urbanismo, Engenharia Civil, Engenharia de Agrimensura e Engenharia Ambiental da UNESC. Uma área de seis hectares foi adquirida pela Prefeitura Municipal de Forquilhinha em 2009, no Bairro Cidade Alta. Nesta área, foi desenvolvido um projeto de urbanização de interesse social de 112 lotes e os projetos arquitetônicos dos embriões para a construção de 108 unidades habitacionais convencionais e de 04 unidades adaptadas. $\mathrm{O}$ projeto, inaugurado em 26/07/2013, teve como objetivo atender moradores de baixa renda remanejados de áreas de risco de rejeito de carvão, ou em situações irregulares às margens do rio Sangão, localizadas no próprio Bairro Cidade Alta.

Revista Extensão em Foco, nº 16, Jul./ Dez. (2018), p. 37 - 54. 
Revista Extensão em Foco, nº 16, Jul./ Dez. (2018), p. 37 - 54. 
Figura 1 - Projeto Bairro Cidade Alta, Forquilhinha (SC)

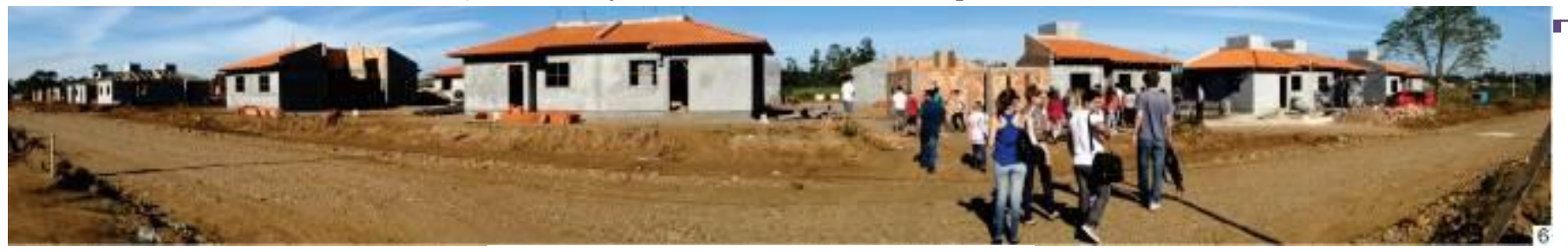

Fonte: Marcelo Cabral Vaz (2010)

O EMI é um escritório permanente que oferece apoio aos projetos de extensão aprovados no âmbito do Programa de Extensão Permanente Habitat + Humano Inclusivo e Sustentável - PEHIS ou provenientes de demandas externas. Possui como objetivo atuar por meio da Assistência Técnica, conforme a Lei 11.888/2008, atendendo às demandas das comunidades organizadas da região de abrangência da Universidade do Extremo Sul Catarinense - UNESC, com renda de até três salários mínimos, e que vivam em assentamentos irregulares/precários ou em situação de risco, sem infraestrutura e/ou equipamentos comunitários e urbanos. O art. $4^{\circ}$, e especialmente o inciso III da Lei de Assistência Técnica (Lei $\mathrm{n}^{\circ} .11 .888$, de 24 de dezembro de 2008) disciplina in verbis:

Art. 4 Os serviços de assistência técnica objeto de convênio ou termo de parceria com União, Estado, Distrito Federal ou Município devem ser prestados por profissionais das áreas de arquitetura, urbanismo e engenharia que atuem como:

I - servidores públicos da União, dos Estados, do Distrito Federal ou dos Municípios;

II - integrantes de equipes de organizações não governamentais sem fins lucrativos;

III - profissionais inscritos em programas de residência acadêmica em arquitetura, urbanismo ou engenharia ou em programas de extensão universitária, por meio de escritórios-modelos ou escritórios públicos com atuação na área;

IV - profissionais autônomos ou integrantes de equipes de pessoas jurídicas, previamente credenciados, selecionados e contratados pela União, Estado, Distrito Federal ou Município.

$\S 1$ o Na seleção e contratação dos profissionais na forma do inciso IV do caput deste artigo, deve ser garantida a participação das entidades profissionais de arquitetos e engenheiros, mediante convênio ou termo de parceria com o ente público responsável.

$\S 20$ Em qualquer das modalidades de atuação previstas no caput deste artigo deve ser assegurada a devida anotação de responsabilidade técnica. (BRASIL, 2008).

A inserção do escritório como estrutura operativa do PEHIS tem como uma das principais estratégias estabelecer a atuação dos acadêmicos em estágios curriculares supervisionados dos cursos da UNACET, como Arquitetura e Urbanismo, Engenharia Civil, Engenharia de Agrimensura, Engenharia Ambiental e podendo se estender para as áreas do Direito, Geografia e Psicologia. Esta atuação denota uma importante interação do meio Revista Extensão em Foco, nº 16, Jul./ Dez. (2018), p. 37 - 54. 
acadêmico com o seu meio social, despertando o senso crítico e possibilitando a aplicação dos saberes teóricos e práticos adquiridos ao longo da formação, ao atuar nas comunidades organizadas da região de abrangência da UNESC.

Figura 2 - Organograma EMI

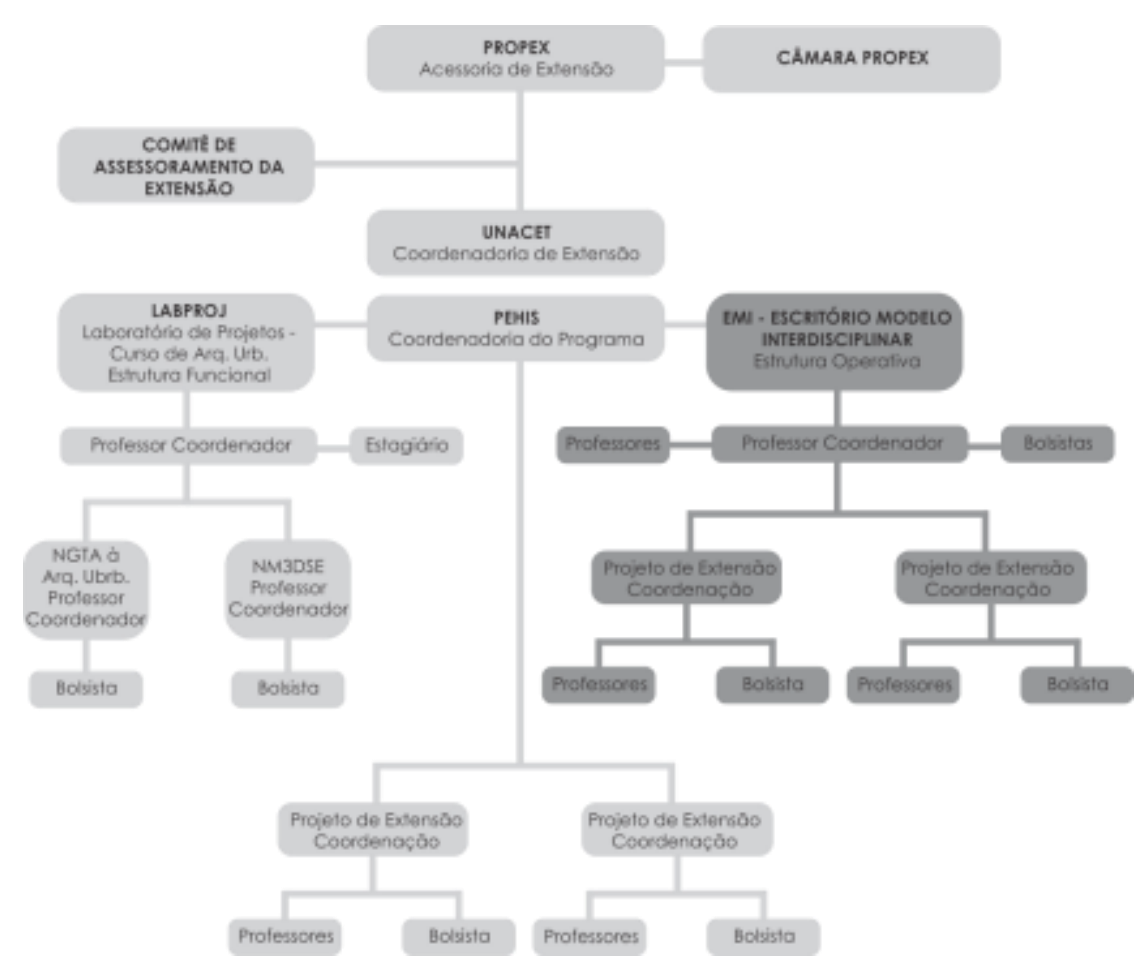

Fonte: Dyene Mafioletti (2017)

Sob esta perspectiva é que se desenvolve o projeto de requalificação do Alvorada Clube, que se localiza entre os Bairros Pinheirinho e Milanese no município de Criciúma, Santa Catarina, Brasil, o qual faz parte da Associação dos Municípios da Região Carbonífera AMREC, que tem como finalidade fortalecer a capacidade administrativa, econômica e social destes municípios e promover a cooperação intermunicipal e intergovernamental.

Revista Extensão em Foco, no 16, Jul./ Dez. (2018), p. 37 - 54. 
Figura 3 - Associação dos Municípios da Região Carbonífera

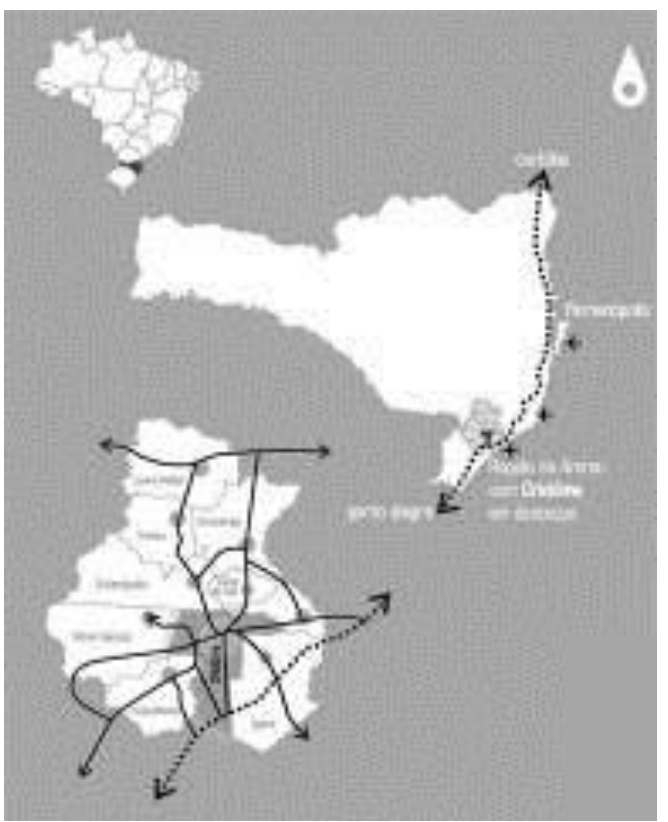

Fonte: Dalana de Matos (2016)

Os dois bairros possuem cerca de 7.621 habitantes. Historicamente, o clube sediou os mais importantes eventos da comunidade local. Sua estrutura física expressa, além do seu valor histórico, uma linguagem tardia do modernismo, constituindo-se em importante acervo local patrimonial a ser preservado.

Figura 4 - Localização Alvorada Clube
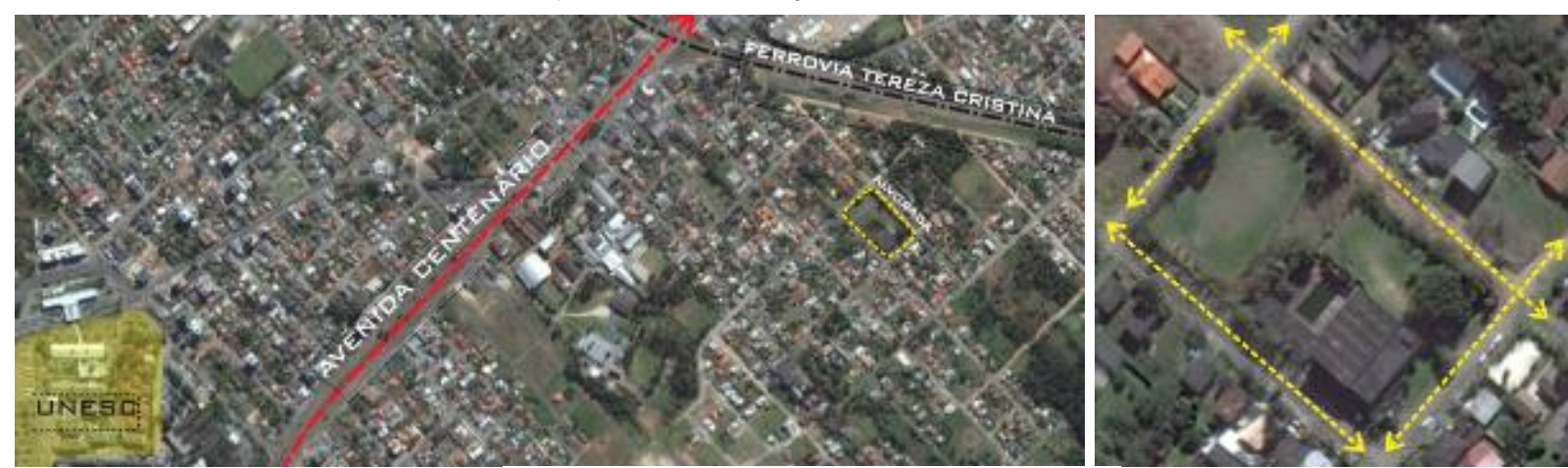

Fonte: Dyene Mafioletti (2017)

Revista Extensão em Foco, no 16, Jul./ Dez. (2018), p. 37 - 54. 
Figura 5- Pavimento Superior e Pavimento Térreo

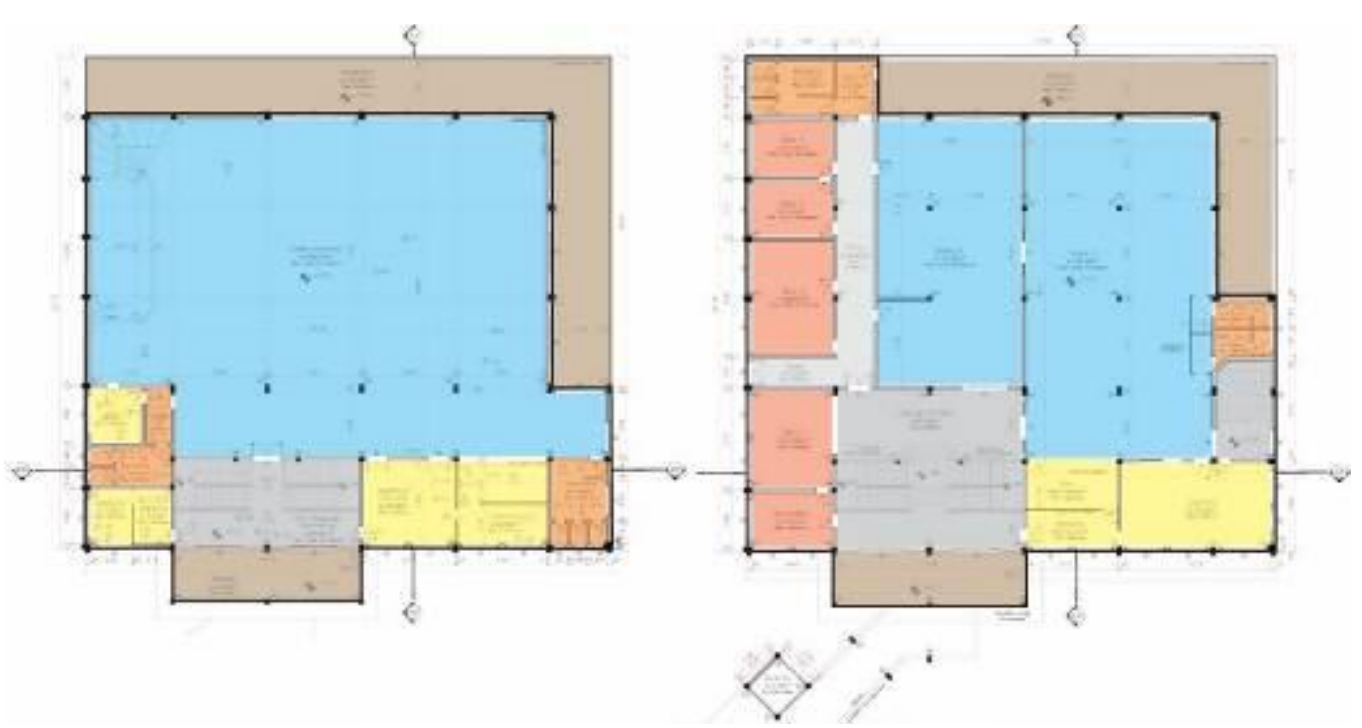

Fonte: Dyene Mafioletti (2017)

- Azul: salão de festas;

- Amarelo: depósito e cozinha;

- Laranja: banheiros;

- Cinza: circulações verticais e hall;

- Marrom: varandas;

- Vermelho: salas de uso geral.

A edificação foi idealizada pelo arquiteto e ex-prefeito de Criciúma (gestão 19771983), Altair Guidi. A edificação expressa uma linguagem tardia do movimento moderno em Criciúma. O clube passou pela administração de dezesseis presidentes.

Revista Extensão em Foco, nº 16, Jul./ Dez. (2018), p. 37 - 54. 
Figura 6- Pavimento Subsolo e Anexo da Piscina
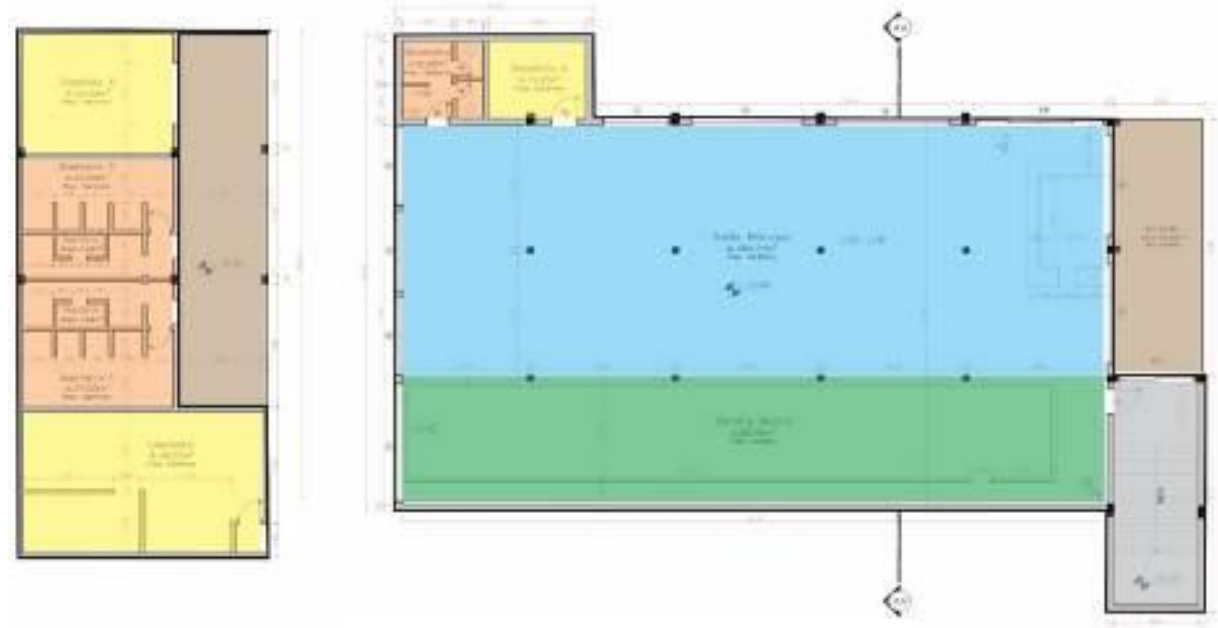

Fonte: Dyene Mafioletti (2017)

- Azul: salão de festas;

- Amarelo: depósito e cozinha;

- Laranja: banheiros;

- Cinza: circulações verticais e hall;

- Marrom: varandas;

- Verde: cancha de bocha.

O conjunto arquitetônico abrange um programa composto por três pavimentos (subsolo, térreo, primeiro pavimento), ampla área externa com campo de futebol e piscina. $\mathrm{O}$ pavimento térreo conta com dois salões de festa, cinco salas de uso flexível, hall de entrada, bar, depósito, cozinha, banheiros feminino, masculino e ampla área de varanda, como mostra a figura 05. O segundo pavimento conta com salão de festa com palco para apresentações, banheiros feminino e masculino, depósito, cozinha, hall e ampla área de varandas.

O pavimento do subsolo é composto por cancha de bocha, bar, salão de jogos, banheiro e depósito. Além disso, conta com acesso direto à piscina e área de lazer que possui um anexo composto por banheiros, vestiários e depósito, como mostra a figura 06.

O clube passou por um período de declínio e acúmulo de dívidas, e atualmente apresenta precariedade em suas instalações e problemas estruturais, esquadrias precárias, mobiliário interno comprometido e incompatibilidade do conjunto arquitetônico mediante as

Revista Extensão em Foco, no 16, Jul./ Dez. (2018), p. 37 - 54. 
normas técnicas e de segurança - adversidades provenientes da ausência progressiva de manutenção preventiva da edificação em todos estes anos, situação observada nas figuras 7-13.

Figuras 7 e 8 - Alvorada Clube
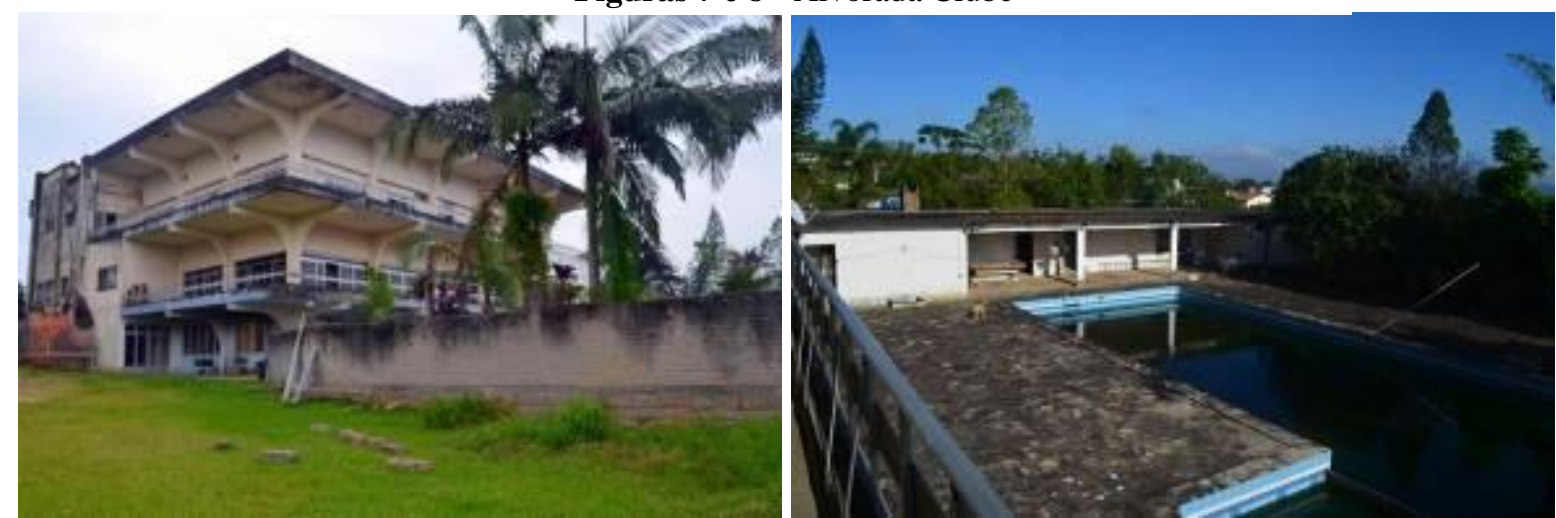

Fonte: Francis Barbosa Júnior (2017)

No início deste ano, a APROFUCRI (Associação dos Professores e Funcionários da FUCRI - Fundação Educacional de Criciúma), que é a mantenedora da UNESC - assumiu a dívida do Alvorada Clube, não obstante, objetivando manter a preservação do patrimônio histórico material e imaterial do conjunto arquitetônico e possibilitando que a comunidade utilize este espaço após a requalificação. Desta forma, a APROFUCRI, estabeleceu um convênio com o Escritório Modelo Interdisciplinar para realizar o levantamento patrimonial do edifício a fim de produzir um estudo preliminar para a recuperação das instalações deste conjunto arquitetônico.

Figuras 9a13 -Alvorada Clube

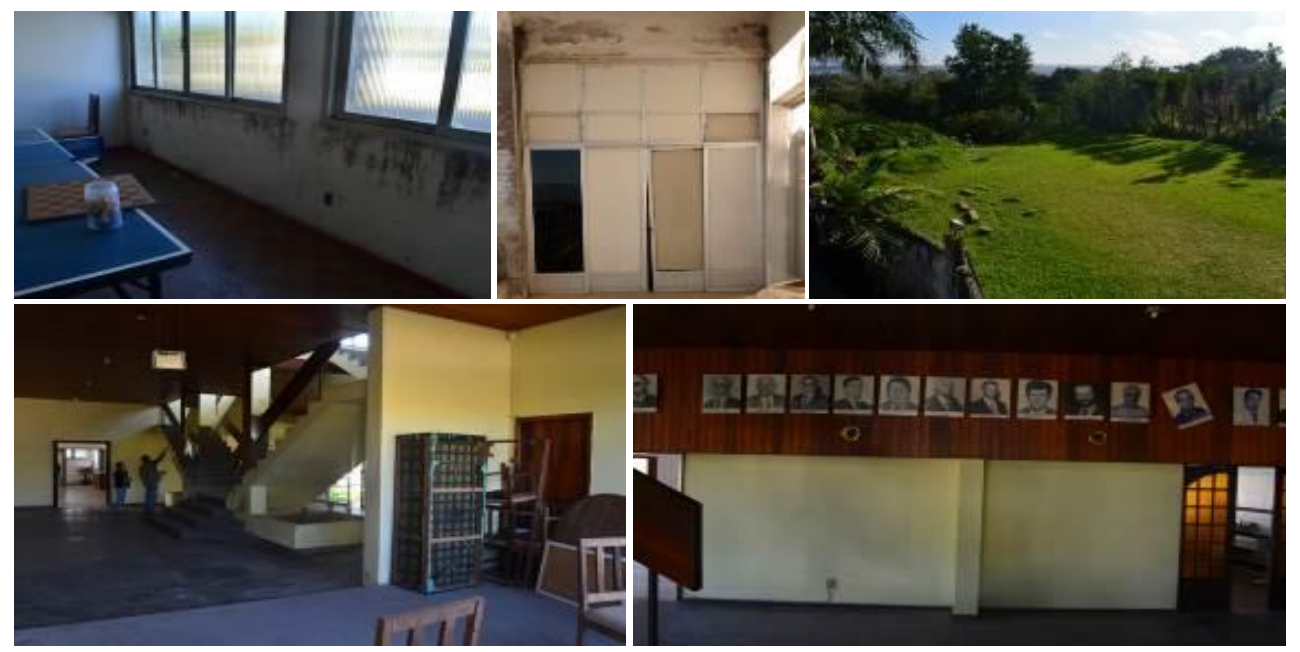

Fonte: Francis Barbosa Júnior (2017)

Revista Extensão em Foco, nº 16, Jul./ Dez. (2018), p. 37 - 54. 
O estudo teve início com visitas exploratórias e de observação no local, junto dos associados, bolsistas e professores, a fim de fazer reconhecimento do edifício e da paisagem local. Posteriormente, o trabalho se estendeu ao seu período mais extenso, a equipe levou cerca de cinco meses para a conclusão do levantamento arquitetônico, topográfico e fotográfico, em vista da inexistência dos desenhos técnicos da edificação e da extensão do espaço. Portanto, de maio a outubro de 2017, os acadêmicos de Arquitetura e Urbanismo, Engenharia Civil e Engenharia de Agrimensura concentraram-se nas medições e representação gráfica da edificação e do terreno, que se constituem de planta de localização e situação, planta do pavimento subsolo, pavimento térreo, pavimento superior, cortes transversais e longitudinais, e fachadas.

De forma paralela, foram realizados os levantamentos fotográficos de todos os pavimentos da edificação, identificando todas as esquadrias e suas condições de preservação, além de louças sanitárias, revestimentos, pisos, forros, equipamentos e quaisquer outros objetos pertencentes ao inventário do Clube, como forma de catalogação e fonte de informação para intervenções posteriores.

Figura 7- Levantamento Arquitetônico, Topográfico e Fotográfico
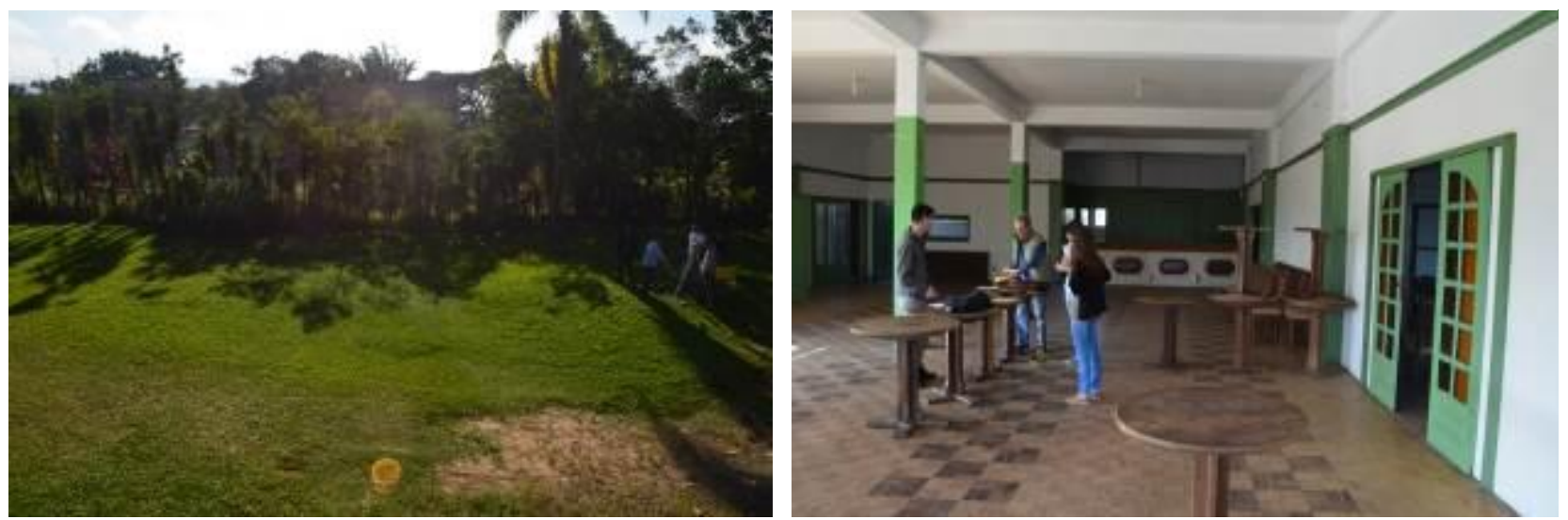

Fonte: Francis Barbosa Júnior (2017)

Concomitantemente, o escritório modelo desenvolveu o partido da área externa do Alvorada Clube, espaço este com urgência inicial de requalificação, desenvolvido por meio de maquetes eletrônicas, plantas, cortes e fachadas, com participação dos bolsistas na elaboração e expressão das ideias e conceitos com orientação dos professores. O partido adotado baseia-se em um programa de necessidades elaborado pela associação APROFUCRI em parceria com o

Revista Extensão em Foco, nº 16, Jul./ Dez. (2018), p. 37 - 54. 
EMI, e que compreende: a redução do campo de futebol, implantação de quiosques para lazer, parque infantil, vagas de estacionamento, vestiários, banheiros e acessibilidade no local. $\mathrm{O}$ processo, ao todo, foi desenvolvido no período de oito meses e realizado de forma colaborativa entre o escritório modelo e a APROFUCRI.

Figura 8- Apresentação do partido para a comissão de associados da APROFUCRI
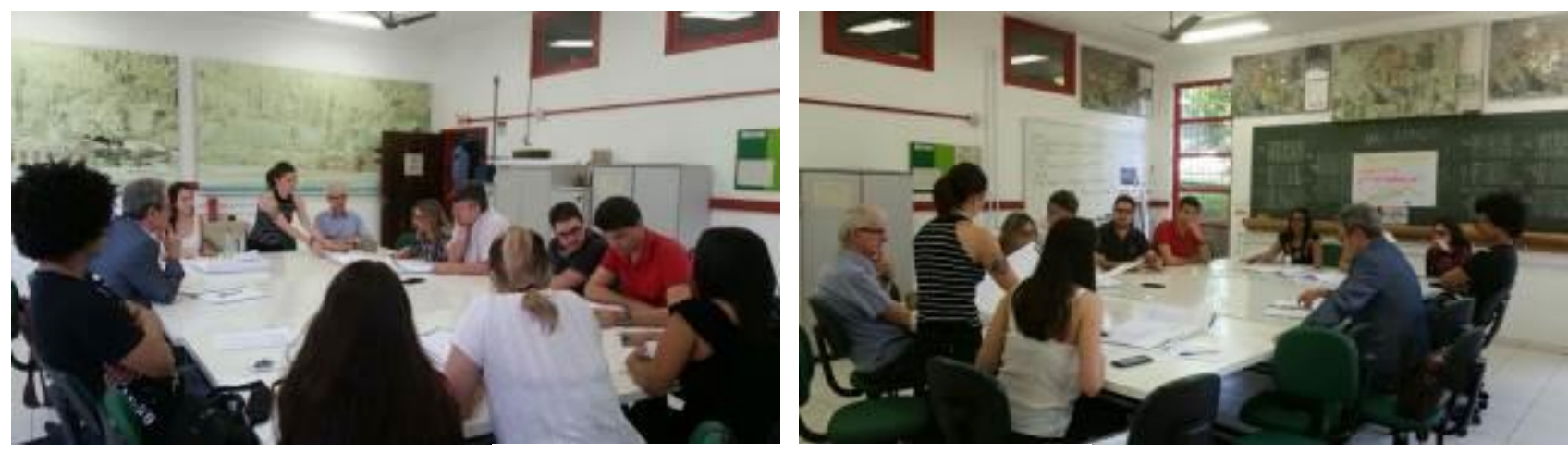

Fonte: Mateus Filisbino Nazário (2017)

\section{RESULTADOS E DISCUSSÕES}

Antes da elaboração do partido de projeto, foi iniciada a etapa de levantamento arquitetônico, que consiste em medir a edificação construída em seus planos verticais e horizontais, a fim de elaborar os desenhos técnicos acerca da edificação com o objetivo de obter um maior entendimento de seus fluxos, ambientes e utilizar nas alterações projetuais posteriores. Para captar todos os detalhes da edificação foram utilizadas várias técnicas, como o desenho à mão esquemático, medir por meio de trenas digitais e/ou mecânicas e, por conseguinte, realizar o desenho em software específico para desenho técnico em arquivo digital. No levantamento foram medidos o perímetro da edificação e seus ambientes internos e externos; a espessura de alvenarias; o comprimento e altura de esquadrias; detalhes estruturais, como degraus, pilares e vigas; diferentes níveis da edificação, e outros aspectos que influem no projeto arquitetônico.

Após a realização de coleta de dados, foram elaborados os desenhos técnicos, com plantas baixas, cortes e elevações, e com este material pronto foi possível ter maior conhecimento sobre toda a complexidade geométrica, construtiva e dimensional da edificação. A realização do levantamento arquitetônico foi um grande desafio, em razão de que a edificação Revista Extensão em Foco, no 16, Jul./ Dez. (2018), p. 37 - 54. 
é ampla e não existia nenhum desenho técnico anterior ou de origem como base, devendo ser iniciado a partir de medições in loco. Concomitantemente, a equipe de acadêmicos de Engenharia de Agrimensura, acompanhados por um professor responsável, realizaram as medidas e o levantamento topográfico necessário para a continuidade das medições. Foram realizadas as locações das edificações e da piscina, assim como árvores existentes, perímetros, divisas, ruas, acessos de pedestres, desníveis e cota zero do projeto.

\section{LEVANTAMENTO FOTOGRÁFICO}

Com a finalidade de levantar, inventariar e diagnosticar o estado de conservação das instalações do edifício do Alvorada Clube, o grupo realizou registro fotográfico de todo o edifício, tanto de patologias e de alguns aspectos da construção para análise como: estrutura, esquadrias, revestimentos de paredes e pisos. As análises do levantamento fotográfico tiveram como objetivo identificar as anomalias da edificação e servir de instrumento para sua restauração, e posterior conservação e manutenção.

O prédio que tem três pavimentos usa elementos construtivos da sua época, sendo comum encontrar madeira, concreto armado, vidro e alumínio em sua técnica construtiva. Cada ambiente foi fotografado, organizado e tabelado, com os devidos diagnósticos como representado nas figuras 9 e 10.

Figura 9-Modelo do Levantamento dos espaços com identificação de materialidade

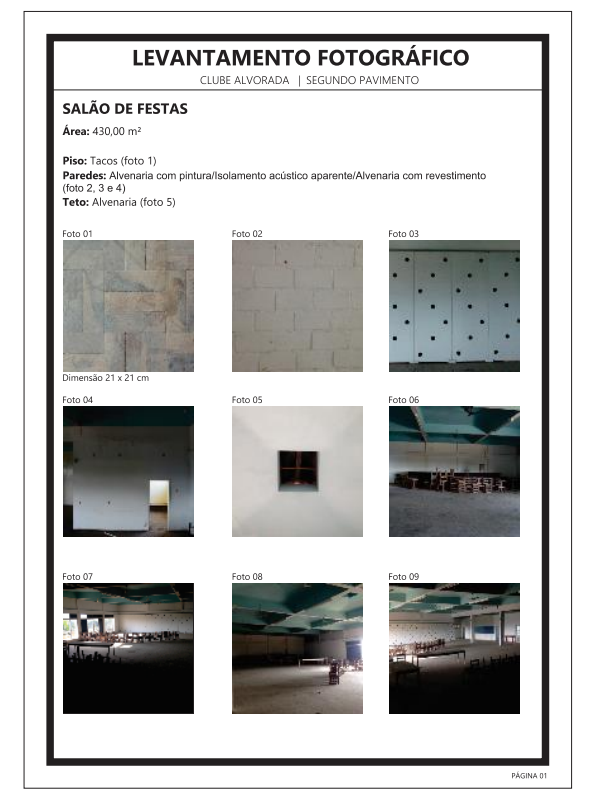

Fonte: Geferson da Rosa (2017)

Revista Extensão em Foco, no 16, Jul./ Dez. (2018), p. 37 - 54. 


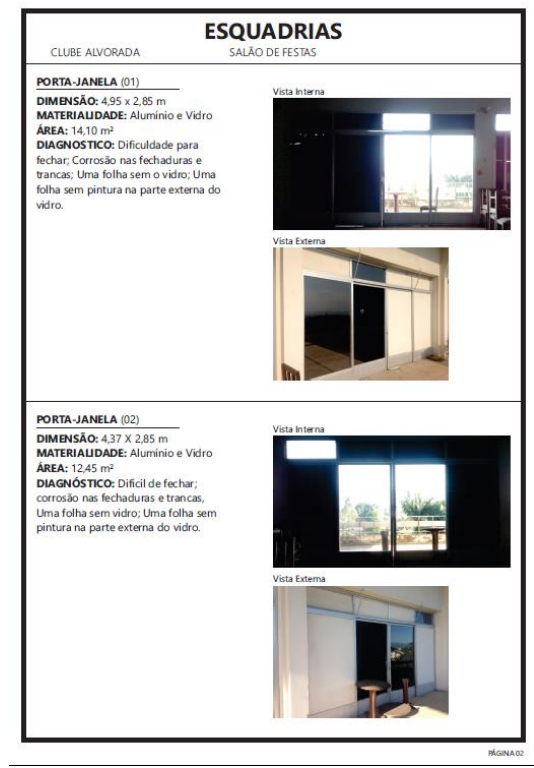

As esquadrias de alumínio e vidro das paredes externas são as mais conservadas, porém os maiores problemas encontrados foram a corrosão e a falta de vidro. Em caso de restauro poucas serão trocadas por completo, porém seus aspectos deteriorados podem ser confundidos por vezes pela sujeira encontrada, tal problema é ocasionada pela ausência de manutençã

Já as portas internas são de madeira e apresentam os maiores problemas de conservação, pois quase todas elas foram atingidas pela umidade ou cupim, além da corrosão nas fechaduras e dobradiças, quando essas existem. É fácil perceber que dificuldades de abrir e fechar as portas são resultados de tais patologias.

Revestimentos das paredes, pisos e teto geralmente tem uma boa conservação, mas a umidade é uma grande causadora de problemas, o que culmina em vários pontos de umidade, principalmente nos tacos de madeira do salão do segundo andar e nas áreas molhadas do Alvorada Clube.

Após visitas ao local e conclusão do levantamento arquitetônico, topográfico e fotográfico, foram iniciados os estudos para a elaboração do partido. A partir do programa de necessidades elaborado anteriormente, em reuniões com a associação APROFUCRI, foram desenvolvidas ideias iniciais para a revitalização das áreas externas de lazer, sendo adotadas diretrizes que expressam melhor os anseios e necessidades da Associação.

Revista Extensão em Foco, nº 16, Jul./ Dez. (2018), p. 37 - 54. 


\section{PARTIDO}

O partido das áreas externas conta com equipamentos em dois níveis, o primeiro no nível do subsolo (nível $-2,89 \mathrm{~m}$ a partir do nível $0,0 \mathrm{~m}$ na rua), onde se localizam o estacionamento e a piscina. O estacionamento possui 49 vagas de carros, sendo estas sombreadas por arborização planejada que complementa a já existente no local. A área de piscina já existente passa a possuir muros baixos, permitindo a visualização do entorno, assim como a implantação de portões maiores de acesso, permitindo a transição fluida para os outros ambientes, garantindo a integração. O segundo nível, localizado a -7,80m em relação ao nível da rua é acessado por meio de escadas e rampas, que permitem passeio e contemplação do espaço. Neste nível estão localizados quiosques, playground, campo poliesportivo com arquibancadas e vestiários. Os sete quiosques dispostos à oeste do terreno conformam um espaço na forma de $\mathrm{C}$ e são compostos por churrasqueiras e bancadas para preparação de alimentos. Os mesmos têm em média área de $46 \mathrm{~m}^{2}$ a $70 \mathrm{~m}^{2}$, podendo abrigar de 20 a 30 pessoas.

Figura 11- Planta Setorizada de Partido

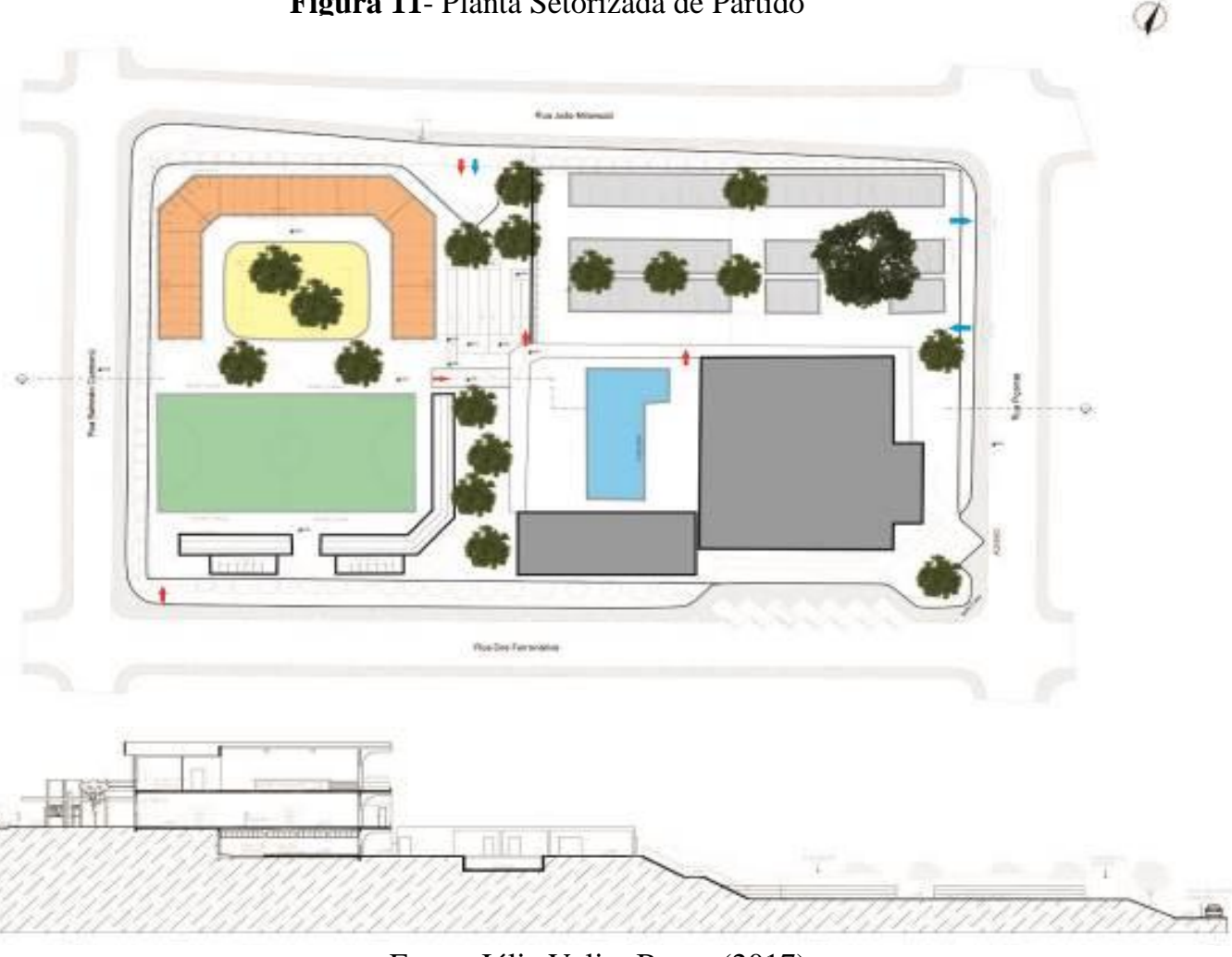

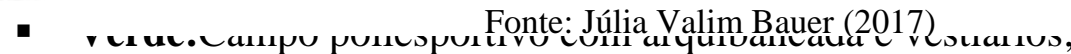

- Cinza claro:Estacionamentos (49 vagas);

- Azul:Piscina;

- Cinza escuro:Edificação.

Revista Extensão em Foco, nº 16, Jul./ Dez. (2018), p. 37 - 54. 
Junto aos quiosques estão localizados banheiros femininos e masculinos, a fim de atender as necessidades desta área de lazer. No centro dos quiosques estão localizados equipamentos de um parque infantil, onde as crianças podem se divertir com supervisão dos familiares. Na região sul do terreno está localizado o campo poliesportivo, com arquibancadas que comportam até 250 pessoas, e em seu espaço posterior estão localizados os vestiários como forma de apoio. Novos acessos foram implantados para as áreas do segundo nível: um acesso localizado perto dos quiosques para carga e descarga, e outro para pedestres, ao lado do campo e vestiários.

Revista Extensão em Foco, nº 16, Jul./ Dez. (2018), p. 37 - 54. 
Figura 10- Imagens do Partido e Levantamento da Edificação (Segundo Pavimento, Térreo e Subsolo respectivamente).
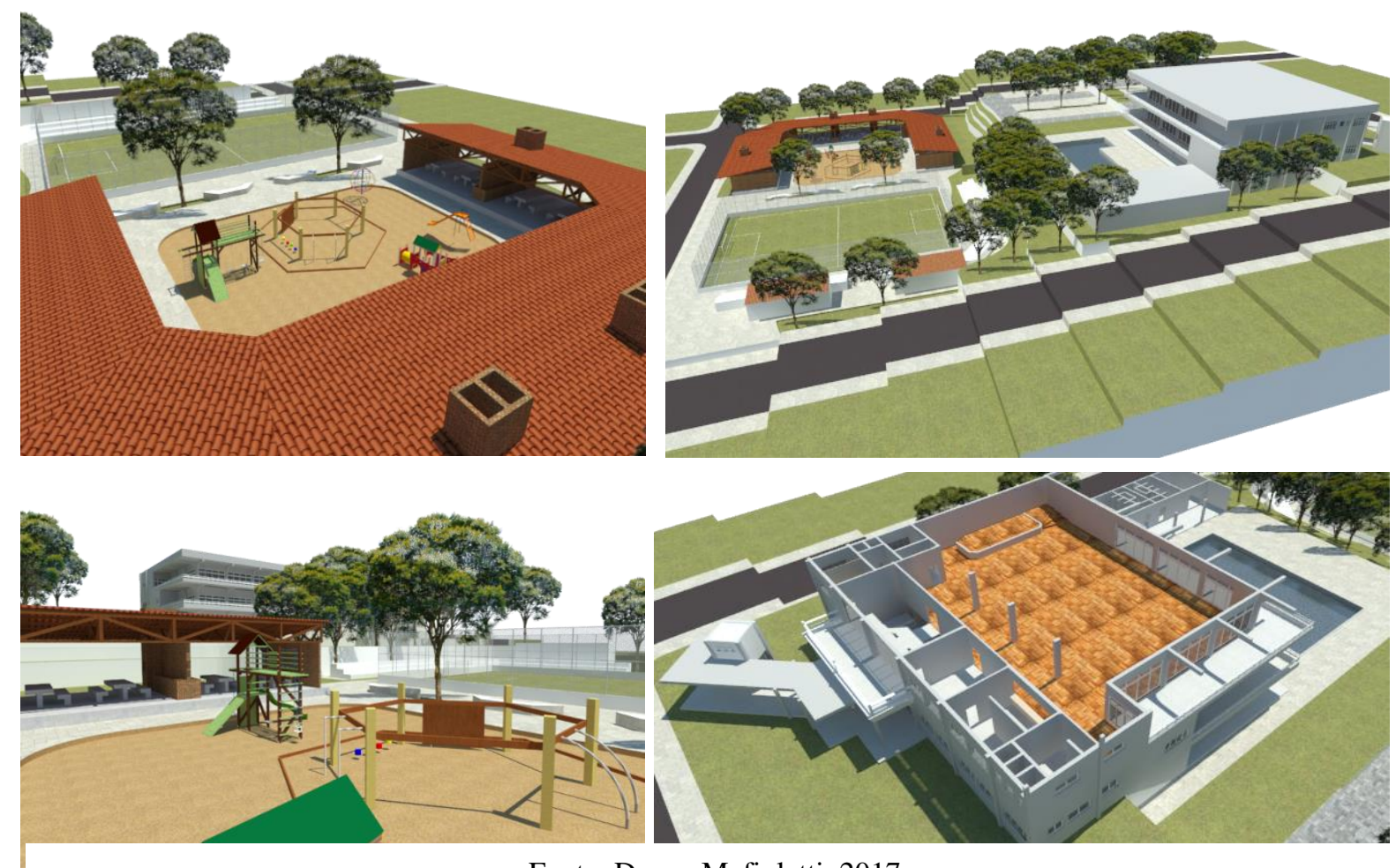

Fonte: Dyene Mafioletti, 2017
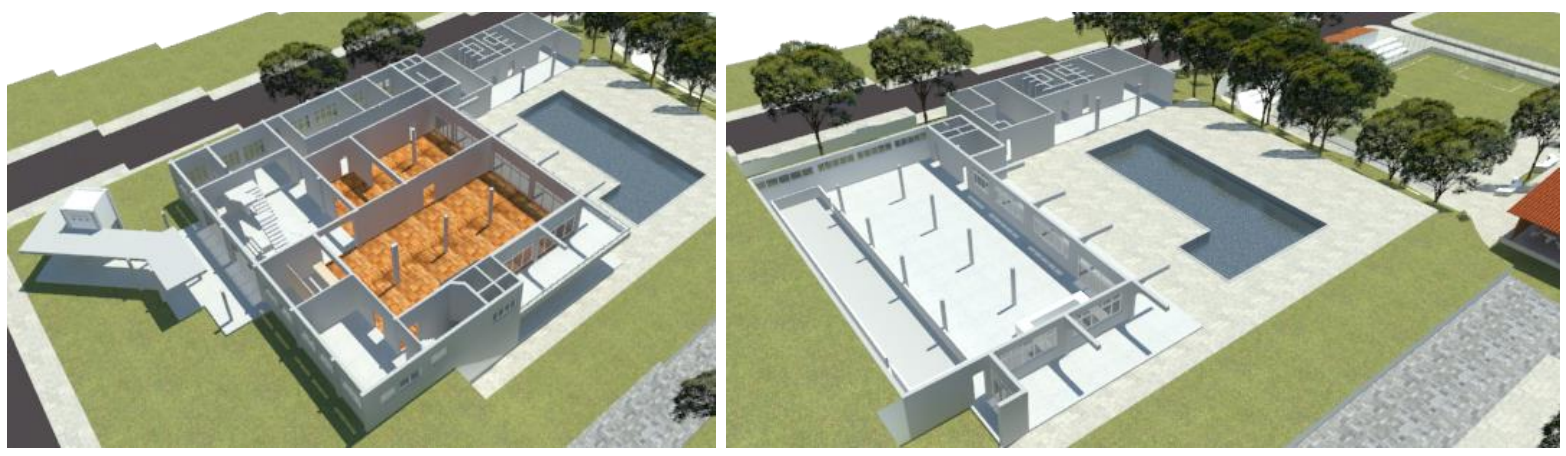

\section{CONCLUSÕES}

A experiência de extensão do Escritório Modelo Interdisciplinar, no levantamento patrimonial e na produção de um partido de projeto arquitetônico do Alvorada Clube aconteceu de forma satisfatória e positiva, por meio da interação universidade-comunidade e da participação ativa dos acadêmicos neste processo. O processo metodológico colaborativo possibilitou confirmar as percepções iniciais do grupo sobre a situação atual da edificação de

Revista Extensão em Foco, nº 16, Jul./ Dez. (2018), p. 37 - 54. 
más condições de conservação, sua potencialidade de uso e por apresentar valor histórico relevante para a comunidade, e também por figurar como um dos importantes edifícios do acervo histórico municipal que expressa uma linguagem tardia do modernismo, no município de Criciúma.

A conjugação desta fase com as próximas etapas do projeto incluem o estudo, diagnóstico e a elaboração de um estudo preliminar da edificação, que visam a recuperação completa das suas instalações por meio de uma prática colaborativa entre o Escritório Modelo Interdisciplinar - EMI da Universidade do Extremo Sul Catarinense - UNESC, a Associação de Professores e Funcionários da UNESC - APROFUCRI e a comunidade dos bairros Pinheirinho e Milanese, em Criciúma/SC. Essa prática, além de possibilitar trocas de saberes entre a universidade e a comunidade, oferece aos discentes oportunidade de experimentar habilidades e competências adquiridas, pela participação na solução de problemas reais inerentes ao seu campo de atuação.

Além disso, essa experiência mostra o potencial que o EMI pode ter enquanto um elemento de vinculação entre o ensino, pesquisa e extensão e na relação entre a Universidade e a sua comunidade de abrangência.

\section{AGRADECIMENTOS E APOIOS}

O Escritório Modelo Interdisciplinar agradece a todos que direta ou indiretamente contribuíram para a realização deste trabalho, em especial à Universidade do Extremo Sul Catarinense - UNESC e à Associação de Professores e Funcionários da Universidade do Extremo Sul Catarinense - APROFUCRI pelo auxílio prestado quando necessário.

\section{REFERÊNCIAS BIBLIOGRÁFICAS}

BRASIL. Decreto $\mathrm{n}^{\circ} 11.888$, de 24 de dezembro de 2008. Assegura às famílias de baixa renda assistência técnica pública e gratuita para o projeto e a construção de habitação de interesse social e altera a Lei no 11.124, de 16 de junho de 2005. In: Planalto, Brasília. Disponível em: <http://www.planalto.gov.br/ccivil_03/_ato2007-2010/2008/lei/111888.htm>. Acesso em Agosto 2017.

Revista Extensão em Foco, nº 16, Jul./ Dez. (2018), p. 37 - 54. 
FeNEA, Federação Nacional de Estudantes de Arquitetura e Urbanismo do Brasil. Escritório modelo de Arquitetura e Urbanismo - EMAU. In: Projetos. Disponível em: $<$ http://www.fenea.org/projetos/EMAU/>. Acesso em Agosto 2017.

ASSOCIAÇÃO BRASILEIRA DE NORMAS TÉCNICAS. NBR 6492: Representação de projetos de arquitetura. Rio de Janeiro: Abnt, 1994. 27 p. Disponível em: $<$ https://docente.ifrn.edu.br/albertojunior/disciplinas/nbr-6492-representacao-de-projetos-dearquitetura>. Acesso em: 10 ago. 2017.

BRASIL. Ministério da Cultura. Instituto do Programa Monumenta Manual de elaboração de projetos de preservação do patrimônio cultural / Elaboração José Hailon Gomide, Patrícia Reis da Silva, Sylvia Maria Nelo Braga. _ Brasília : Ministério da Cultura, Instituto do Programa $\quad$ Monumenta, $2005 . \quad 76$ p.Disponível em: <http://portal.iphan.gov.br/uploads/publicacao/CadTec1_Manual_de_Elaboracao_de_Projetos _m.pdf >. Acesso em: 08 ago. 2017.

Revista Extensão em Foco, nº 16, Jul./ Dez. (2018), p. 37 - 54. 